Journal of Machine Engineering, 2020, Vol. 20, No. 2, 104-113

ISSN 1895-7595 (Print) ISSN 2391-8071 (Online)

Received: 04 December 2019 / Accepted: 11 February 2020 / Published online: 24 June 2020

CVD diamond coated tools, CFRP machining, drilling

\author{
Eckart UHLMANN ${ }^{1,2}$ \\ Walter REIMERS ${ }^{3}$ \\ Daniel HINZMANN ${ }^{2 *}$ \\ Gerret CHRISTIANSEN ${ }^{2}$ \\ Katrin BÖTTCHER ${ }^{3}$
}

\title{
WEAR EVALUATION OF CVD DIAMOND COATED HIGH-PERFORMANCE DRILLING TOOLS FOR MACHINING OF CARBON FIBER REINFORCED PLASTICS (CFRP)
}

\begin{abstract}
The application of carbon fiber reinforced plastics (CFRP) as lightweight construction material in aerospace industry is based on the favorable weight-to-strength ratio. But the inherent material properties pose great challenges for the tool- as well as the manufacturing industry. In terms of economic industrial production processes, the quality of machined workpieces exhibits poor reproducibility combined with high tool wear. For this purpose, high-performance drilling tools with different CVD diamond coatings and carbide substrates with varying binder content were tested and analyzed in order to assess coating adhesion and workpiece quality. Due to a reduction of cobalt binder within the tungsten carbide-based tool substrates, an increase of tool performance regarding borehole quantity until coating delamination is demonstrated. While the reduction of tool wear on the rake face of the drilling tools can be correlated with the cutting tool performance, the online monitoring of cutting forces does not explicitly identify damaged cutting tools during machining.
\end{abstract}

\section{INTRODUCTION}

Innovative materials such as CFRPs are increasingly being used in applications for structure- and weight-optimized components [1,2]. In particular within the aerospace industry, the primary goal is to maintain a favorable weight-to-strength ratio while simultaneously weight reduction and the interrelated resulting fuel savings are achieved [3,4]. By adapting the material properties, opportunities for component development create a dynamic field of application. The components used are prefabricated as close to the final contour as possible in order minimize costs for subsequent finishing process operations $[5,6]$. Due to technolocally demanding requirements regarding workpiece quality

\footnotetext{
${ }^{1}$ Fraunhofer Institute for Production Systems and Design Technology (IPK), Berlin, Germany

${ }^{2}$ Institute for Machine Tools and Factory Management (IWF) - TU Berlin, Germany

${ }^{3}$ Institute for Materials Science and Technologies; Metallic Materials (MW) - TU Berlin, Germany

*E-mail: Daniel.hinzmann@iwf.tu-berlin.de https;//doi.org/10.36897/jme/119640
} 
while high tool wear occurs, the machining of such materials faces a challenge for the manufacturing industry $[7,8]$. Based on the use of hard cutting materials such as diamond which is characterized by the combination of mechanical properties such as hardness and wear resistance, the economical processing of these materials can be achieved [9, 10]. When machining CFRP materials, workpiece layer delamination is the most common defect with primary damage during withdrawal as well as entrance of the tool $[11,12]$. By that, the laminate layers are separated from each other due to compression induced by the cutting tool. In particular, drilling causes layer peeling during tool withdrawal. In addition, fiber protrusions in which one or more fibers are not completely separated as well as workpiece material chipping where fibers do not break during the cutting process weaken the matrix $[13,14]$. Independently of regarded machining process, due to uniform and reproducible wear protection on complex tool geometries, chemical vapor deposition (CVD) is used industrially for tool coating of cobalt-bonded tungsten carbide (WC-Co) substrate materials when machining CFRP $[15,16]$. The targeted process control during the coating process allows producing various layer morphologies such as microcrystalline, nanocrystalline as well as multi-layer structures where coating thickness ranges from $s_{D}=6$ to $20 \mu \mathrm{m}$ on thin film tools. Microcrystalline layer structures are characterized by a columnar crystal growth with an average crystal size of $d_{\mathrm{Dia}}=30 \mu \mathrm{m}$. However, due to morphology the high hardness is accompanied by roughness represented by an arithmetical mean deviation of the assessed profile $R a \approx 1.9 \mu \mathrm{m}$ on the rake face.

Nanocrystalline layer structures are characterized by a quasi-isotropic arrangement of diamond crystals with an average crystal size of $d_{\text {Dia }}=100 \mathrm{~nm}$. Based on the crystal size, the smooth surface with an arithmetical mean deviation of the assessed profile $R a \approx 1.0 \mu \mathrm{m}$ is particularly suitable for machining adhesive materials [17,18]. Crack propagation is hindered by the amount of grain boundaries compared to the microcrystalline morphology. The alternating combination of both micro- and nanocrystalline layer morphologies combines the properties of both layer structures and completes the industrially offered wear protection coatings based on CVD diamond, denoted as multi-layer morphology [19, 20]. Although CVD diamond thin film tools offer considerable potential for machining high performance materials, spontaneous and premature tool failure can limit process reliability [21, 22]. The remaining issues regarding coating adhesion and restricted process reproducibility therefore confine the extent of application [23].

Existing substrates based on WC-Co compositions vary, for example, in terms of grain size $d_{K}$ and cobalt content $w_{C o}$. The resulting mechanical properties show various possible applications for the use as cutting tool substrate material. Because of the affinity of CVD diamond towards iron and iron-based workpiece materials, a CVD diamond coated cutting tool is limited to the machining of non-ferrous materials, such as CFRPs as well as aluminum alloys [24].

Currently there is insufficient understanding of the wear behavior of CVD diamond coated tools regarding spontaneous tool failure. Within the scope of various scientific studies, the wear behavior was investigated and the coating quality as well as the coating and substrate residual stress were identified as essential influencing factors on the coating adhesion as well as the tool performance respectively [25-27]. In addition, it was highlighted that a long tool life is promoted by residual compressive stresses in the CVD diamond coating [28-30]. In the 
context of this contribution, performed machining tests and wear behavior of various substrate-coating combinations are analyzed in particular.

\section{CUTTING TOOLS AND MACHINE SYSTEM}

Machining tests were carried out with WC-Co-based CVD diamond coated tools commonly applied for setting rivet holes in aircraft construction. The macro geometry of the double-edged stage twist drills features a diameter of $d=5.6 \mathrm{~mm}$, a point angle $\alpha=130^{\circ}$ and a right-hand helix at an angle of $\delta=40^{\circ}$, see Fig. 1 .

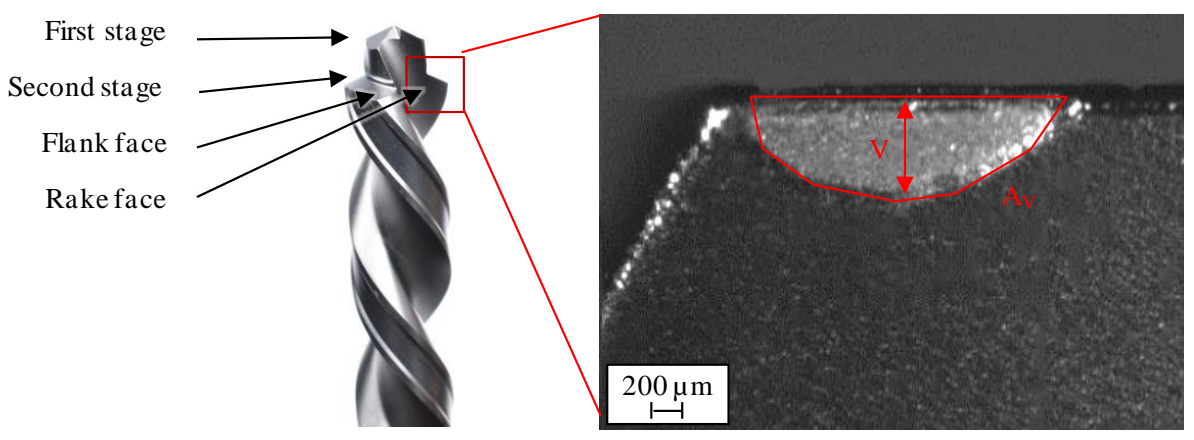

Fig. 1. Double-edged stage twist drill macro-geometry as well as illustration of assessment regarding tool wear $V$ and wear surface $A_{V}$ on the rake face

It is noted that he macro-geometry of the tool is not an object of this investigation and will not be examined in detail. All substrate-coating combinations, i.e., tool specifications used are set to a cutting edge radius of $r_{a}=15 \pm 3 \mu \mathrm{m}$ with an average coating thickness of $s_{D}=12 \pm 2 \mu \mathrm{m}$. Focus of this study is tool behavior regarding coating adhesion as a function of the carbide substrate. The tools used vary due to the WC-Co substrate which can be found in Table 1.

Table 1. Substrate material properties

\begin{tabular}{|c|c|c|c|c|}
\hline $\begin{array}{c}\text { Cutting tool } \\
\text { substrate }\end{array}$ & $\begin{array}{c}\text { Cobalt content } \\
w_{C o} \\
{[\text { wt. } \%]}\end{array}$ & $\begin{array}{c}\text { Grain size } \\
d_{K} \\
{[\mu \mathrm{m}]}\end{array}$ & $\begin{array}{c}\text { Vickers hardness } \\
\text { HV30 } \\
{[-]}\end{array}$ & $\begin{array}{c}\text { 3-Point bending strength } \\
\sigma_{b}\end{array}$ \\
\hline WC-6Co & 6 & 0.8 & $1.945 \pm 60$ & $3.826 \pm 750$ \\
\hline WC-10Co & 10 & 0.8 & $1.658 \pm 23$ & $4.066 \pm 532$ \\
\hline WC-5Co & 5 & 0.8 & $1.896 \pm 45$ & $3.571 \pm 152$ \\
\hline
\end{tabular}

${ }^{1}$ Measurement procedure according DIN EN ISO 6507.

${ }^{2}$ Measurement procedure according to DIN EN ISO 3327.

Finest grain carbides with grain size $d_{K}=0.8 \mu \mathrm{m}$ were used for all tool specifications. Within the WC-Co substrates, the cobalt content was varied. Substrates with a content of $w_{\mathrm{Co} 1}=6$ wt. $\% \mathrm{Co}, w_{\mathrm{Co} 2}=10 \mathrm{wt} . \% \mathrm{Co}$ and $w_{\mathrm{Co} 3}=5$ wt. $\%$ Co were used. All substrates 
underwent subsequent CVD diamond tool coating where nanocrystalline (Nano) and two multi-layer morphologies with either an individual layer thickness of $t_{\text {Multi2 }}=2 \mu \mathrm{m}$ (Multi 2) or an individual layer thickness of $t_{\text {Multil }}=1 \mu \mathrm{m}$ (Multi 1) were deposited.

Technological investigations were carried out on a machining center of type Ultrasonic C260 Composites manufactured by Sauer GmbH, Stipshausen, Germany. The CFRP workpiece material with a panel thickness of $t=15 \pm 1 \mathrm{~mm}$ serves as industrial reference used in aeronautical wing construction. To evaluate the tool performance, a continuous measurement of the process forces during drilling was carried out. For this purpose, a 9125A rotary cutting force dynamometer from Kistler Instrumente AG, Winterthur, Switzerland was used in order to document the feed force $F_{f}$. With a measuring frequency of $f=1000 \mathrm{~Hz}$ the measuring signal was scanned.

The test parameters were kept constant for all tests whereby this evaluation is based on five tests per tool specification. A cutting speed of $v_{\mathrm{c}}=105 \mathrm{~m} / \mathrm{min}$ and a feed of $f=0.06 \mathrm{~mm}$ was chosen based on akin industrial manufacturing processes. Tool wear documentation was continuously carried out on the rake face of the drills' second stage at an interval of $N=10$ holes regarding the rake face tool wear $V$ as well as its corresponding accumulative wear surface $V_{\mathrm{A}}$. For this purpose, the tool was removed from the machine tool and examined by light microscopy. The occurrence of the first coating delamination on the tool surface defines the wear criterion of the tests which is based on the identification of initial exposition of substrate material via light microscopy. Subsequently, an additional further $N=100$ holes were drilled with the same tool in order to investigate the wear behavior progression after the initial coating delamination after which the end of experiment is reached. By assessing the cutting tool performance concerning tool life, cutting forces and tool wear, the development of reliable CVD diamond coated tools with focus on the machining of CFRP components is being addressed.

\section{TOOL PERFORMANCE AND WEAR ANALYSIS}

It is assumed that the wear on the second stage occurs in particular due to the tool geometry present. An example of tool wear on the rake face of the second stage of the drill for a WC-6Co tool substrate combined with a nanocrystalline CVD diamond coating is given in Fig. 2.

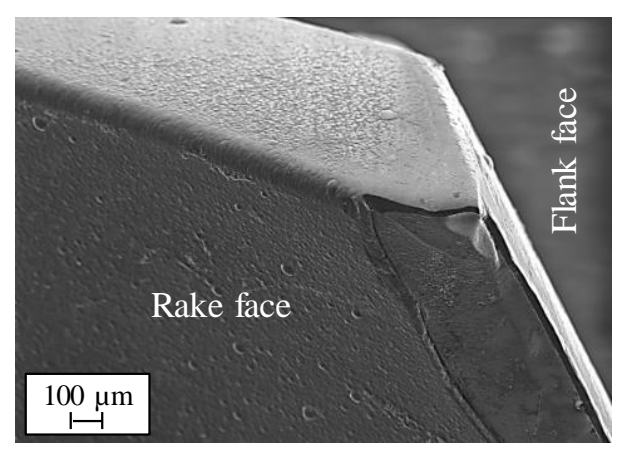

Fig. 2. SEM image of nanocrystalline CVD diamond coated WC-6Co cutting edge 
The basic mechanisms of tool wear are comparable for all tool specifications. Essentially, the dominant wear occurs on the rake face whereby spontaneous coating delamination is induced. In addition, there is abrasive wear of the CVD diamond coating on the flank face surface. Here, the CVD diamond coating is smoothened by the machined carbon fibers and the surface roughness peaks of the coating are removed. However, there is no measurable change in coating thickness. It is particularly noticeable that there is hardly any coating delamination on the flank face of the tools. This only results after significant damage to the rake face of the tool is initialized. After coating delamination on the rake face, the exposed WC-Co substrate is usually significantly damaged whereby continuous wear progression of the cutting edge results. The hard metal substrate material is not able to withstand the thermomechanical load during the cutting process. Due to wear progression, the cutting edge radius $r_{a}$ increases and simultaneously contributes to elevated process forces such as feed force $F_{f}$ since material removal is mechanically obstructed.

a WC-6Co
WC-10Co
a WC-5Co
M No consideration in machining trials
Machine Tool:
Ultrasonic C260 Composites, SAUER GMBH
Tool:
Double-edged step twist drill
Workpiece:
PR-DU CS 600/1250 FT 109133
Process parameter:
Feed rate $\quad \mathrm{v}_{\mathrm{f}}=360 \mathrm{~mm} / \mathrm{min}$
Rotational speed $\mathrm{n}=60001 / \mathrm{min}$
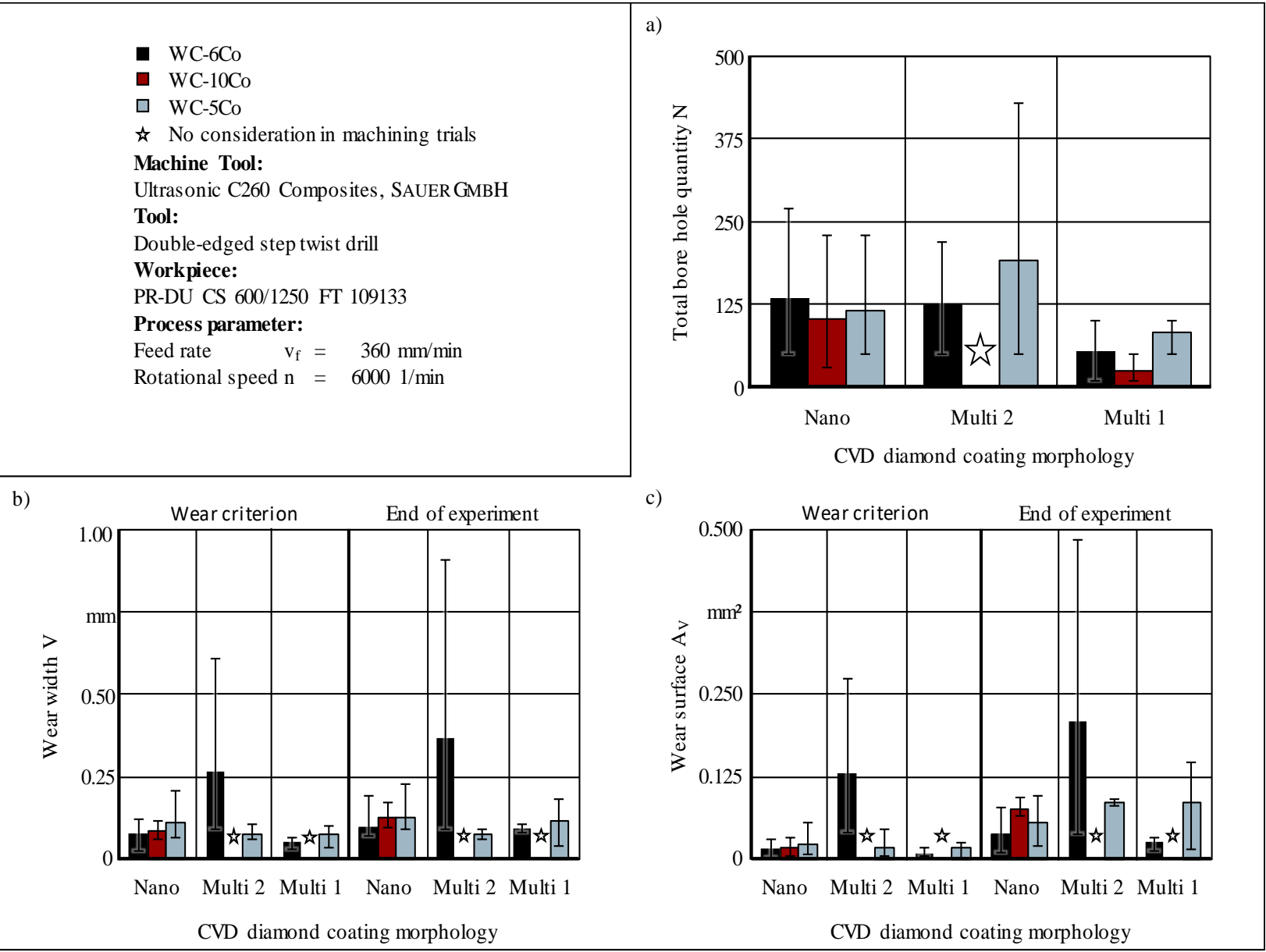

Fig. 3. Total bore hole quantity related to applied tool specification

The tool performance regarding total bore hole quantity $N$, wear mark $V$ and accumulative wear surface $A_{V}$ are illustrated in Fig. 3. In respect to the average total bore hole quantity $N$ as well as its corresponding standard deviation, comparable results are achieved 
with Nano CVD diamond coating for all hard metal substrates, see Fig. 3a. Considering Multi 2 as well as Multi 1 coating, WC-5Co offers the best tool performance with an average bore hole quantity of $N_{\text {Multi2,WC-5Co }}=190$ and $N_{\text {Multi1,WC-5Co }}=84$ respectively. In comparison, WC-6Co tool specifications achieved an average bore hole quantity of $N_{\text {Multi2,WC-6Co }}=123$ and $N_{\text {Multi1,WC-6Co }}=53$. Even though WC-10Co substrate shows comparable results with Nano coating morphology, the substrate demonstrates no potential for multi-layer coating. It either shows poor initial coating adhesion concerning Multi 2 resulting in an exclusion from machining trials or was outperformed regarding Multi 1 morphology. Figures $3 \mathrm{~b}$ and $3 \mathrm{c}$ illustrate wear width $V$ as well as its corresponding accumulative wear surface $A_{\mathrm{V}}$. Its respective progress reaching the wear criterion, i.e., first coating delamination, until the end of experiment is illustrated.

Although the best tool performance with an average total bore hole quantity of $N_{\text {Multi2,WC-5Co }}=190$ is achieved with Multi 2 coating in combination with WC-5Co substrate, wear width $V$ as well as wear surface $A_{V}$ show comparable low values with $\mathrm{V}_{\text {Multi2,WC-5Co }}=0.07 \mathrm{~mm}$ and $A_{V \text {,Multi2,WC-5Co }}=0.87 \mathrm{~mm}^{2}$ at the end of the experiment. The high deviation throughout Nano as well as Multi 2 coating morphology is minimized by the application of Multi 1 CVD diamond coating morphology. This results in lower overall tool performance regarding bore hole quantity whereby an increase in process reliability of the tools is achieved.

Until the end of experiment, all tool specifications show a comparable wear condition. Due to the quantitative assessment regarding tool performance as well as the performed wear analysis, the results show the potential of carbide substrate with low cobalt content for the deposition of a CVD diamond coating in this particular cutting tool application.

\section{PROCESS FORCE MEASUREMENT}

Within this investigation, the process forces were measured continuously for all machining tests carried out. Thereby, feed force $F_{f}$ was evaluated. Due to the symmetrical cutting edge position of the double-edge stage twist drill, the determination of cutting force $F_{\mathrm{C}}$ can only be measured indirectly. Also, the measurement of the passive force $F_{P}$ is not suitable since it is equally opposed at the individual cutting edge resulting in mutual cancellation. As expected, the feed forces of each tool specification differ slightly based on tool specification, i.e., CVD diamond coating morphology as well as substrate material. An exemplary course of feed force development regarding best tool performance in each case in respect to total bore hole quantity $N$ is given in Fig. 4. Even though the second stage of the tool wears out significantly during machining reaching the tool wear criterion, i.e., coating delamination, the feed force $F_{\mathrm{f}}$ increases only slightly.

While machining with Nano CVD diamond coating, adverse feed force development is documented whereas a comparable average bore hole quantity is achieved. Regarding WC-6Co substrate, the tendency for feed force decrease results after the first coating delamination at $N_{\mathrm{WC}-6 \mathrm{Co}}=150$. In this case the coating delamination leads to a reduction of the total cutting edge radius $r_{a}$. By that, an advantageous micro-geometry is produced 
randomly responsible for the decrease of feed force $F_{f}$. Thereby, the lowest value with a final feed force $F_{f, \text { WC-6Co }}=37 \mathrm{~N}$. On the contrary, substrate material WC-10Co shows an increase after coating delamination manifestation resulting in a final feed force at the end of experiment of $F_{f, \mathrm{WC}-10 \mathrm{Co}} \approx 55 \mathrm{~N}$ which represents the highest value present, see Fig. 4a. Regarding Multi 2 CVD diamond coating both substrates included in machining trials show comparable force development averaging on $F_{f \text {,average }} \approx 50 \mathrm{~N}$ but differ in total bore hole quantity, see Fig. $4 b$.

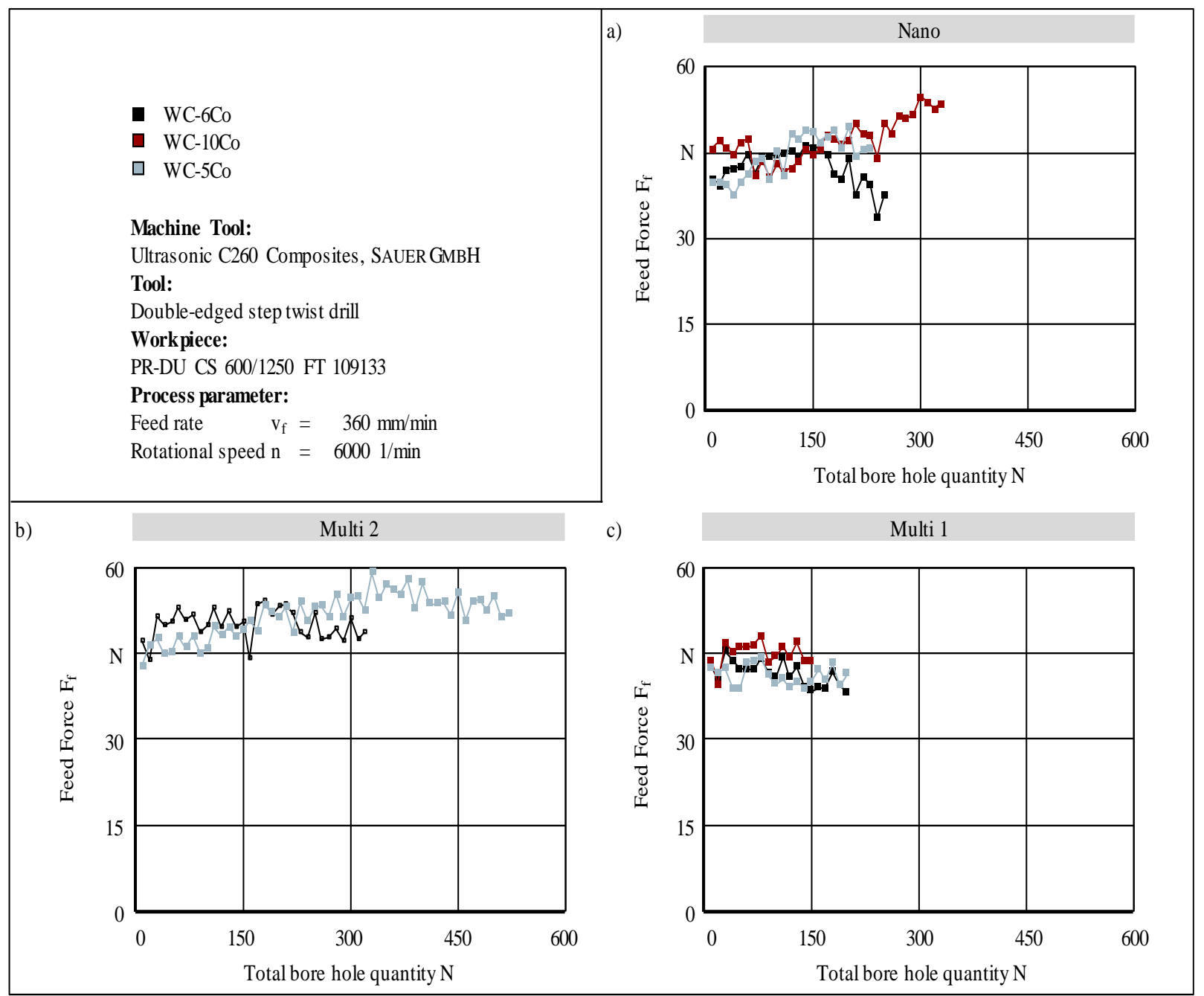

Fig. 4. Development of feed force $F_{f}$ in respect to total bore hole quantity

It is to note that the superior tool performance Multi 2 CVD diamond coating deposited on WC-5Co substrate is accomplished by simultaneously maintaining little deviation of the average feed force. This indicates proper coating adhesion as well as favorable wear development. Figure 4c illustrates the comparable feed force development of Multi 1 CVD diamond coating on the investigated substrate materials. In general, an average reduction of bore hole quantity of $50 \%$ was achieved with these tool specifications compared to all substrates deposited with Multi 2 CVD diamond coating. Nevertheless, constant low feed 
forces were produced averaging at $F_{\text {f,average }} \approx 40 \mathrm{~N}$ regarding $\mathrm{WC}-6 \mathrm{Co}$ as well as WC-5Co substrates presenting the lowest constant process forces development within this study. However, tool wear $V$ as well as the corresponding accumulative wear surface $A v$ show comparable manifestation with simultaneous high deviations of wear development results. The before mentioned superior process reliability of Multi 1 coatings deposited on WC-6Co as well as WC-5Co is therefore due to a lower thermo-mechanical load during the machining process by $20 \%$ compared to the same tool specifications deposited with Multi 2 CVD diamond coating.

\section{SUMMARY AND OUTLOOK}

The investigations described provide insights into the interactional relationship between CVD diamond coating morphology, substrate material and coating adhesion in the machining of CFRP material used in aircraft construction. In the performed machining tests, potential for the CVD diamond coating with the lowest cobalt content of $w_{C o}=5$ wt. \%, i.e., WC-5Co for the deposited coating morphologies Nano, Multi 2 and Multi 1 is shown. The combination of CVD diamond coating morphology and substrate material offer a varying tool performance in respect to total bore hole quantity, tool wear as well as process forces. Even though substrate materials with a cobalt content of $w_{C o}=10 \mathrm{wt}$. \% generally offer a more suitable mechanical profile when machining difficult-to-machine workpiece materials due to higher bending strength and the resulting resistance against impact loads, low cobalt content shows superior tool performance in this application. Thereby the following conclusions can be drawn for the investigated application of the cutting tools:

- Compared to WC-based substrate materials with conventional cobalt content $w_{C o} \geq$ 6 wt. \% Co, lower cobalt content in combination with a CVD diamond coating offers an overall favorable tool performance regarding tool life, wear and process force;

- The interaction of tool life and process reliability is based on the applied tool specification;

- Superior tool life of tool specifications with Multi 2 CVD diamond coatings deposited on low cobalt contend based WC is accompanied by high deviations regarding bore hole quantity;

- Process reliability of tool specifications with Multi 1 CVD diamond coatings is based on low process force development which is due to favorable coating adhesion.

After the described investigations, the different tool specifications will be further investigated with regard to coating adhesion. In particular, the influence of coating and substrate residual stresses on coating adhesion will be analyzed. The identification of specific conditions which have a positive influence on the overall tool life will be addressed.

\section{ACKNOWLEDGEMENTS}

This publication is based on the results of the DFG UH 100/200-1 and DFG RE 688/71-1 research projects funded by the German Research Foundation (DFG). 
REFERENCES

[1] WITTEN E., SAUER M., KÜHNEL M., 2017, Composites Marktbericht 2017, https://www.avktv.de/files /20171026_avkccev__marktbericht_2017.pdf, (Accessed on November $5^{\text {th }}, 2019$ ).

[2] M'SAOUBI R., AXINTE D., SOO S.L., NOBEL C., ATTIA H., KAPPMEYER G., ENGIN S., SIM W.M., 2015, High Performance Cutting of Advanced Aerospace Alloys and Composite Materials, CIRP Ann. - Man. Technol., 64, 557-580.

[3] UHLMANN E., RICHARZ S., SAMMLER F., HUFSCHMIED R., 2016, High Speed Cutting of Carbon Fibre Reinforced Plastics, Proc. CIRP Manufacturing, 6, 113-123.

[4] WEGENER K., KUSTER F., WEIKERT L., WEISS L., STIRNIMANN J., 2017, Success Story Cutting, Proc. CIRP, 46, 512-524.

[5] KARATAS M.E., GÖKKAYA H., 2018, A Review on Machinability of Carbon Fiber Reinforced Polymer (CFRP) and Glass Fiber Reinforced Polymer (GFRP) Composite Materials, Def. Tec., 14, 318-326.

[6] BYRNE G., AHEARNE E., COTTERELl M., MULlANY B., O’DONNELl G.E., SAMMLER F., 2016, High Performance Cutting (HPC) in the New Era of Digital Manufacturing - A Roadmap, Proc. CIRP, 46, 1-6.

[7] SORRENTINO L., TURCHETTA S., BELLINI C., 2018, A New Method to Reduce Delaminations During Drilling of FRP Laminates by Feed Rate Control, Comp. Struct., 186, 154-164.

[8] HALIM N.F.H.A., ASCROFT H., BARNES S., 2017, Analysis of Tool Wear, Cutting Forces, Surfaces Roughness and Machining Temperature During Finishing Operation of Ultrasonic Assisted Milling (UAM) of Carbon Fiber Reinforced Plastics (CFRP), Proc. Eng., 184, 185-191.

[9] UHLMANN E., SAMMLER F., RICHARZ S., HEITMÜLLER F., BILZ M., 2014, Machining of Carbon Fibre Reinforced Plastics, Proc. CIRP, 24, 19-24.

[10] WANG X., SHEN X., Zeng C., Sun F., 2018, Combined Influences of Tool Shape and As-Deposited Diamond Film on Cutting Performance of Drills for CFRP Machining, Surf. Coat. Technol., 347, 390-397.

[11] RAMIREZ C., POULACHON G., ROSSI F., M'SAOUBI R., 2014, Tool Wear Monitoring and Hole Surface Quality During CFRP Drilling, Proc. CIRP, 13, 163-168.

[12] HINTZE W., CLAUSEN R., SCHÜTTE C., KROLL K., 2018, Evaluation of the Total Cutting Force in Drilling of CFRP: A Novel Experimental Method for the Analysis of the Cutting Mechanism, Prod. Eng., 12/3-4, $431-440$

[13] KUO C., WANG C., KO S., 2018, Wear Behaviour of CVD Diamond-Coated Tools in the Drilling of Woven CFRP Composites, Wear, 398-399, 1-12.

[14] ZHANG J., YUAN Y., ZHANG J., 2018, Cutting Performance of Microcrystalline, Nanocrystalline and Dual -Layer Composite Diamond Coated Tools in Drilling Carbon Fiber Reinforced Plastics, Appl. Sci., 8, 1642.

[15] UHLMANN E., REIMERS W., SAMMLER F., 2012, Werkzeugauslegung zur Bearbeitung von Leichtbauwerkstoffen, wt online, 6, 217-229.

[16] ISMAIL S.O., DHAKAL H.N., POPOV I., BEAUGRAND J., 2016, Comprehensive Study on Machinability of Sustainable and Conventional Fibre Reinforced Polymer Composites, Eng. Sci. Technol. Int. J., 19/4, 2043-2052.

[17] BOBZIN K., 2017, High-Performance Coatings for Cutting Tools, CIRP J. Manuf. Sci. and Technol., 18, 1-9.

[18] SKORDARIS G., BOUZAKIS K.-D., KOTSANIS T., BOUMPAKIS A., STERGIOUDI F., CHRISTOFILOS D., LEMMER O., KÖLKER W., WODA M., 2019, Effect of the Crystallinity of Diamond Coatings on Cemented Carbide Inserts on Their Cutting Performance in Milling, CIRP Annals, 68/1, 65-68.

[19] MOHR M., CARON A., HERBECK-ENGEL P., 2014, Youngs Modulus, Fracture Strength, and Poisson's Ration of Nanocrystalline Diamond Flims, J. Appl. Phys., 116/12, doi.org/10.1063/1.4896729, (Accessed on November $\left.5^{\text {th }}, 2019\right)$.

[20] SAMMLER F., 2015, Steigerung der Nutzungspotenziale von CVD-diamantbeschichteten Werkzeugen, Fraunhofer Verlag, Stuttgart.

[21] LI J., YU X., ZHANG Z., 2019, Exploring a Diamond Film to Improve Wear Resistance of the Hydraulic Drilling Impactor, Surf. and Coat. Technol., 360, 297-306.

[22] AHMED F., 2012, Deformation and Damaging Mechanisms in Diamond Thin Films Bonded to Ductile Substrates, University Nürnberg-Erlangen, http://nbn-resolving.de/urn:nbn:de:bvb:29-opus-39101, (Accessed on October 17 , 2019).

[23] HINZMANN D., UHLMANN E., 2019, Einsatzverhalten von CVD-Diamantdünnschichtwerkzeugen, wt online, $7 / 8,563-569$.

[24] KLOCKE F., 2018, Fertigungsverfahren 1: Zerspanung mit geometrisch bestimmter Schneide, Springer Verlag, Wiesbaden. 
[25] UHLMANN E., SAMMLER F., MEIXNER M., 2015, Analysis of Residual Stresses and Wear Mechanisms of HF -CVD Diamond Coated Cemented Carbide Tools, J. Prod. Eng. Res. Develop., 9, 99-107.

[26] SKORDARIS G., BOUZAKIS K.-D., CHARALAMPOUS P., KOTSANIS T., BOUZAKIS E., LEMMER O., 2016, Effect of Structure and Residual Stresses of Diamond Coated Cemented Carbide Tools on the Film Adhesion and Developed Wear Mechanisms in Milling, CIRP Annals, 65/1, 101-104.

[27] SALGUEIREDO E., AMARAL M., ALMEIDA F.A., FERNANDES A.J.S., OLIVEIRA F.J., SILVA R.F., 2013, Mechanical Performance Upgrading of CVD Diamond Using the Multilayer Strategy, Surf. and Coat. Technol., 236, 380-387.

[28] UHLMANN E., KÖNIG J., SAMMLER F., RICHARZ S., 2014, Tribology of Treated and Coated Cutting Tool Surfaces, In: Q.J. WANG, Y.W. CHUNG (Eds.), Encyclopedia of Tribology, Springer, Boston.

[29] GAYDAYCHUK A., ZENKIN S., LINNIK S., 2019, Influence of Al-Si-N Interlayer on Residual Stress of CVD Diamond Coatings, Surf. and Coat. Technol., 357, 348-352.

[30] HOCHENG H., CHEN C.C., TSAO C.C., 2018, Prediction of Critical Thrust Force for Tubular Composite in Drilling-Induced Delamination by Numerical And Experimental Analysis, Comp. Struct., 203, 5660-573.

[31] DIN EN ISO 6507-1, 2018, Metallic Materials - Vickers Hardness Test - Part 1: Test Method, International Organization for Standardization, Geneva.

[32] DIN EN ISO 3327, 2009, Hardmetals - Determination of Transverse Rupture Strength, International Organization for Standardization, Geneva. 